\title{
AUDIÊNCIA DE CUSTÓDIA E EFICIÊNCIA PROCESSUAL
}

\section{CUSTODY HEARING AND PROCEDURAL EFFICIENCY}

\section{Luiz Fernando Pereira de Oliveira ${ }^{1}$}

Resumo: O presente trabalho tem o objetivo de avaliar a possibilidade de a audiência de custódia ser utilizada para a citação do réu. A partir de uma abordagem histórica e jurídica do direito à liberdade, bem como por intermédio de uma correta compreensão do princípio da eficiência administrativa, acredita-se ser possível defender a criação, por meio de lei, de novas modalidades de citação e intimação fictas. No dia da audiência de custódia, o juiz poderia definir um prazo para que o custodiado retornasse ao fórum para se inteirar sobre o andamento do seu processo, sob pena de ser considerado citado. Ainda, no dia de seu comparecimento, seria desde já intimado para, querendo, participar da audiência de instrução e julgamento. A proposta é compatível com o regime das liberdades, com o direito de defesa e também com a obrigação constitucional de alocação eficiente dos limitados recursos públicos brasileiros.

Palavras-chave: Liberdade. Audiência de custódia. Princípio da eficiência. Direito de defesa. Citação.

ABSTRACT: The present paper aims to examine the possibility of using the custody hearing for summons to a defendant. From a historic and legal approach of the right of freedom, as well as through of a correct understanding of the principle of administrative efficiency, it is possible to defend the creation, by law, of new modalities of supposed summon and intimation. On the day of the custody hearing, the judge could define a deadline for the person in custody to return to the court in order to take notice of the progress of your lawsuit, under sentence of being considered summoned. Likewise, on the appointed day to return, the person would be also notified to attend the trial, if he wants.

1. Juiz Substituto da $24^{\mathrm{a}}$ Circunscrição Judiciária (Balneário Camboriú/SC). E-mail: luizfernandooliveira@tjsc.jus.br 
The proposal is compatible with the rights of freedom, of defense and, also, with the constitutional obligation of efficient allocation of Brazil's limited public resources.

Keywords: Freedom. Custody hearing. Efficiency principle. Right of defense. Summons.

\section{INTRODUÇÃO}

Para o bem ou para o mal, a audiência de custódia presencial é uma realidade no Brasil ${ }^{2}$. Já que o juiz e os servidores necessariamente irão se encontrar com o cidadão preso em flagrante, não seria adequado, em

2. Em outra oportunidade, seria conveniente analisar a real necessidade da audiência de custódia presencial no Brasil. Aparentemente, a obrigação do ato presencial sobrecarrega o erário, desaloca recursos públicos que poderiam estar sendo melhor empregados na (re)estruturação, por exemplo, do sistema carcerário e, o que é mais grave, lança indevida suspeição não apenas sobre o Ministério Público, a quem compete o controle externo da atividade policial, mas também sobre o próprio defensor, a quem caberá todo o patrocínio técnico do acusado ao longo (e mesmo depois) de todo o processo penal. Fosse o Brasil um país rico, com boa estrutura carcerária, boas estradas e contingente adequado de servidores nos órgãos de persecução criminal, talvez a apresentação física se justificasse. Infelizmente, não é o caso. O que parece, e o que demanda maior aprofundamento, é que existe, no Brasil, uma preocupação excessiva com o cumprimento de certas formalidades, como se isso bastasse para o reposicionamento do país em termos de adequada tutela e promoção de direitos fundamentais. Algumas formas são absorvidas à rotina judicante de maneira apressada e, na prática, no conjunto, se prestam apenas a oferecer um simulacro, um invólucro de civilização avançada. O Brasil, mesmo com todas as suas dificuldades, assegura ao cidadão preso a presença física de um juiz em menos de 24 horas de sua prisão, pouco importando os custos e as dificuldades logísticas para tanto. Todavia, tão logo encerrado o ato, já não se preocupa mais com as condições de tempo e espaço, do encarceramento daquele cidadão. Ou seja, além do prejuízo para a generalidade das pessoas, a audiência presencial também não satisfaz as reais necessidades do encarcerado, que, mais do que receber uma pequena e rápida amostra de um sistema funcional, certamente anseia por um procedimento globalmente mais atento à tutela e promoção de seus direitos fundamentais. 
termos financeiros e de eficiência administrativa, aproveitar o ato para outros fins?

Como se sabe, salvo raras exceções não previstas em lei, o procedimento é o seguinte: após a realização da audiência de custódia, se o indivíduo for solto, o máximo que se obtém em termos de eficiência administrativa é a fixação da medida cautelar de manutenção do endereço atualizado nos autos, facilitando, com alguma sorte, o trabalho dos poucos oficiais de justiça do sistema de justiça brasileiro. Nada mais.

Portanto, a prática exige que os escassos servidores confeccionem e distribuam mandados de citação para que seja localizado aquele indivíduo que há poucos meses saiu pela porta do fórum. Com sorte, ele será encontrado no endereço disponibilizado no dia da audiência de custódia. Caso contrário, a via crucis já é conhecida: os autos permanecerão em incontáveis idas e vindas entre o gabinete judicial, o Ministério Público e o oficial de justiça, todos em busca do cidadão recentemente entrevistado, até que, finalmente, depois de expressivo gasto de tempo e recurso, o processo será suspenso com fundamento no art. 366 do código de processo penal.

Neste espaço, pretende-se defender uma via alternativa: o aproveitamento da audiência de custódia para a fixação de um calendário de citação/intimação do acusado, dispensando a prática de atos cartoriais e de diligências pelos oficiais de justiça, e reconhecendo na pessoa presa um ser humano capaz, livre e autônomo para deliberar sobre os caminhos de sua própria vida, sem espaço para qualquer tipo de voluntarismo paternalista judicial.

\section{A DEFESA DA LIBERDADE}

É preciso, agora, fixar duas premissas, uma mais geral, que diz com o próprio desenvolvimento da liberdade humana, e outra jurídica, que parece suficiente para sustentar a conclusão apresentada ao final. 


\subsection{A liberdade no pensamento histórico}

A relação entre o Estado e o particular é objeto de uma série de discussões ao longo da história do pensamento ocidental. Para os fins do que se pretende sustentar, é desnecessário percorrer toda a evolução da defesa da liberdade do indivíduo.

Aqui, basta analisar o pensamento de Karl Popper, um dos mais importantes filósofos liberais contemporâneos. A escolha de Popper se deu por conta de sua vigorosa defesa da liberdade e do reconhecimento do ser humano como um agente autônomo e capaz de fazer as escolhas substantivas de sua própria vida, arcando, naturalmente, com as consequências daí decorrentes.

Llosa (2019, p. 114), analisando a obra do pensador austríaco, faz duas importantes reflexões:

Provavelmente nenhum pensador fez da liberdade uma condição tão imprescindível para o ser humano como Popper. Para ele, a liberdade não só garante formas civilizadas de existência e estimula a criatividade cultural: ela é o resquício básico do saber, o exercício que permite ao homem aprender com seus próprios erros e, portanto, superá-los (...) Popper enxerga um pânico inconsciente à responsabilidade que a liberdade impõe ao indivíduo, que por isso mesmo tende a sacrificar esta para se livrar daquela.

A liberdade, filha e mãe da racionalidade e do espírito crítico, põe nos ombros do ser humano uma carga pesada: ter que decidir por si mesmo o que lhe convém e o que o prejudica, como enfrentar as incontáveis provocações da existência, se a sociedade funciona como deveria ser ou se é preciso reformá-la. É um fardo pesado demais para muitos homens. E, por isso, diz Popper, ao mesmo tempo que despontava a sociedade aberta - na qual a razão tomou o lugar da irracionalidade, o indivíduo passou a ser protagonista da história e a liberdade começou a substituir a escravidão de outrora - também nascia, e pela mão de pensadores notáveis como Platão e Aristóteles, um impulso contrário, para impedi-la e negá-la, e para ressuscitar ou conservar aquela velha sociedade tribal na qual o homem, abelha dentro da colmeia, fica isento de tomar decisões individuais, de enfrentar o desconhecido, de ter que resolver por sua conta e risco os infinitos problemas de um universo emancipado dos deuses 
e demônios da idolatria e da magia em permanece desafio à razão dos indivíduos soberanos.

Do pensamento de Popper, pretende-se extrair a seguinte conclusão: um indivíduo verdadeiramente livre não precisa da tutela de quem quer que seja, muito menos do Estado, para escolher, dirigir e protagonizar os rumos de sua própria história.

A liberdade pressupõe a ausência de censura na tomada de decisões estritamente individuais. Um país que trata seus cidadãos como pessoas livres franqueia a cada um deles a plena capacidade de deliberar sobre a sua vida, sem rotas ou determinações. Reconhece que ninguém melhor que o próprio indivíduo para decidir e determinar o que lhe convém. Admite que escolhas infelizes poderão ser realizadas, mas, justamente por terem sido desimpedidas, serão suportadas por seus próprios e exclusivos autores.

Em outras palavras: é autoritário, porque contrário à liberdade, supor que pessoas adultas e plenamente capazes não saberão defender os seus próprios interesses, necessitando, em consequência, do apoio de um agente externo, alguém que lhe direcione os passos e organize suas necessidades e ambições.

Uma segunda contribuição importante de Karl Popper é o método de progresso social que ele chama de "engenharia gradual ou fragmentária”. Prossegue-se na descrição de Llosa (2019, p. 122):

Uma vez que nos damos conta de que não podemos trazer o céu para a terra, mas só podemos melhorar um pouco as coisas, vemos também que só podemos melhorá-las pouco a pouco: mediante contínuos reajustes nas partes, em vez de propor a reconstrução total da sociedade. Avançar assim tem a vantagem de que a cada passo pode-se avaliar o resultado obtido e retificar o erro a tempo, aprender com ele. O método revolucionário impede essa possibilidade porque, em seu desprezo pelo particular, em sua fixação obsessiva pelo todo, rapidamente se afasta do concreto. Transforma-se numa atividade distante do real, que só obedece a um modelo abstrato, alheio à experiência, frente ao qual, por querer fazê-lo coincidir com a realidade social, terma sacrificando o resto, do racionalismo até a liberdade, e até mesmo, às vezes, o simples bom senso. 
O método proposto é um convite ao progresso. Em vez de se buscar reformas substantivas e complexas, que, em uma democracia deliberativa de dimensões continentais, exige amplos e improváveis consensos, deve se concentrar em pequenas alterações. Avanços parcelares e contínuos, com entusiasmo mais sobre o rumo do que quanto à velocidade.

\subsection{A liberdade no direito brasileiro}

Neste tópico, o que se pretende demonstrar é que o conceito de liberdade proposto, com todas as suas nuances e implicações, por Karl Popper está expressamente previsto no ordenamento jurídico brasileiro.

Em 2011, enquanto esteve em período de pesquisa na Universidade de Harvard, o professor Luís Roberto Barroso se dedicou ao estudo do princípio da dignidade da pessoa humana, disposto como um dos fundamentos da República Federativa do Brasil (art. $1^{\circ}$, inciso III, da Constituição da República Federativa brasileira).

Em sua conclusão, o professor decompõe conteúdo mínimo do princípio da dignidade humana em três partes: (i) valor intrínseco, (ii) autonomia e (iii) valor comunitário.

Neste estudo, interessa o conceito proposto de autonomia. Conforme a análise de Barroso (2012, p. 81):

A autonomia é o elemento ético da dignidade humana. É o fundamento do livre arbítrio dos indivíduos, que lhes permite buscar, da sua própria maneira, o ideal de viver bem e de ter uma vida boa. A noção central aqui é a de autodeterminação: uma pessoa autônoma define as regras que vão reger a sua vida [...]. A autonomia, portanto, corresponde à capacidade de alguém tomar decisões e de fazer escolhas pessoais ao longo da vida, baseadas na sua própria concepção de bem, sem influências externas indevidas.

A descrição do professor, coincidente com o liberalismo popperiano, parece ser reforçada por uma análise abrangente da legislação brasileira. É que a plena capacidade civil é alcançada aos 18 anos, quando 
então as intervenções do Estado na vida privada se tornam episódicas e pontualmente justificadas ${ }^{3}$.

Em parcial conclusão, pode-se dizer que também o direito brasileiro exige que o indivíduo seja tratado como um fim em si mesmo, como um agente moral autônomo e capaz de, sem qualquer influência ou condicionamento externo, decidir por si mesmo os rumos de sua própria vida, assumindo os riscos e benefícios de suas escolhas desembaraçadas.

\section{A DEFESA DA EFICIÊNCIA}

A emenda constitucional $n^{\circ}$ 19/98 acrescentou a eficiência dentre os princípios basilares da administração pública brasileira. A ideia existente à época era promover verdadeira transformação cultural do setor público do país, que deixaria o modelo burocrático rumo ao programa gerencial.

Bresser Pereira (2006, p. 24), Ministro da Administração Federal e Reforma do Estado e, portanto, artífice da reforma constitucional, a defendeu nos seguintes termos:

A explicação é simples: os cidadãos estão se tornando cada vez mais conscientes de que a administração pública burocrática não corresponde às demandas que a sociedade civil apresenta aos governos no capitalismo contemporâneo. Os cidadãos exigem do Estado muito mais do que o Estado pode oferecer. E a causa imediata da lacuna que assim se cria não é apenas fiscal, como observou O'Connor (1973), nem apenas política, como Huntington (1968) destacou; é também administrativa. Os recursos econômicos e políticos são por definição escassos, mas é possível superar parcialmente essa limitação com o seu uso eficiente pelo Estado, quando não se pode contar com o mercado, isto é, quando a alocação de recursos pelo mercado não é solução factível, dado seu caráter distorcido ou dada

3. Dentre os institutos, pode-se citar o da curatela, que pressupõe o prévio reconhecimento da incapacidade civil. Quanto à legislação, o estatuto do índio (lei $\left.\mathrm{n}^{\circ} 6.001 / 73\right)$ e a lei de inclusão da pessoa com deficiência $\left(\mathrm{n}^{\circ} 13.146 / 15\right)$ são exemplos da excepcionalidade da intervenção estatal na vida privada, somente justificada, e ainda assim em níveis mínimos, quando se reconhece que determinado grupo de pessoas não se encontra em plena condição de deliberar sobre a integralidade de suas necessidades. 
sua incompletude. Nesse caso, a função de uma administração pública eficiente passa a ser valor estratégico, ao reduzir a lacuna que separa a demanda social e a satisfação dessa demanda.

Ou seja, ao menos desde 1998, a gestão eficiente do dinheiro público (do povo) é uma obrigação de natureza constitucional.

É regra básica de economia, de acordo com Mankiw (2020, p.4), que "a tomada de decisões exige escolher um objetivo em detrimento de outro (tradeoff)" e que "o custo de oportunidade de um item é aquilo que você abre mão para obtê-1o".

Em outras palavras: não existem escolhas neutras. Decisões alocativas são implicitamente desalocativas, de modo que, se o Estado gasta dinheiro com determinado procedimento, ele estará, necessariamente, deixando de investir em outras áreas. Se, no âmbito da administração judicial, um servidor se ocupa de determinado processo ou expediente, ele, por consequência, estará preterindo outros tantos.

Em um país como o Brasil, com invencíveis demandas sociais e no qual tramitam, de acordo com o relatório do CNJ de 2019, quase 78 milhões de ações no Poder Judiciário, é especialmente relevante que a alocação de seus escassos recursos (dinheiro e tempo) seja realizada da forma mais racional possível.

\section{A AUdiênCIA DE CUSTÓdIA E O CALENDÁRIO PROCESSUAL}

A tese que se pretende defender é a seguinte: no dia da audiência de custódia, o juiz terá a opção de fixar determinado prazo para que o flagranteado retorne para ser citado. Se ele comparecer, será pessoalmente citado, bem como desde já intimado para o dia da audiência de instrução e julgamento. Caso contrário, será considerado revel, prosseguindo-se o processo penal normalmente.

Conforme exposto anteriormente, vive-se em um país livre, que trata e reconhece as pessoas como iguais, como agentes autônomos e amplamente capazes de tutelarem seus próprios interesses, sem qualquer necessidade de intervenção de quem quer que seja. Excepcionalmente, 
quando as circunstâncias exigem (regime das incapacidades), aí sim o Estado está autorizado a avançar sobre a vida privada, rompendo a histórica barreira representada pela liberdade frente à força do poder político.

Além de se viver em um país que trata seus cidadãos capazes como pessoas adultas e plenas, esse país é obrigado, por expressa determinação constitucional, a alocar seus recursos de maneira adequada e racional, deles extraindo toda a potência. Neste ponto, não se trata apenas de cumprir simples comando legal, mas sim de reconhecer que o país é essencialmente pobre, carente em quase tudo em termos sociais.

O projeto constitucional, assentado sobre a generosa promessa de superação de um persistente histórico de desigualdade, somente pode ser viabilizado mediante o emprego satisfatório do dinheiro do povo.

Volta-se ao tema central: não se justifica o gasto de tempo e de dinheiro para localizar a citar uma pessoa que há poucos meses deixou a porta do fórum. É totalmente adequado às premissas acima de que o juiz tenha condições, de acordo com a realidade de sua unidade, de fixar um prazo adequado para que o custodiado, em liberdade, retorne ao fórum, caso queira, para ser cientificado do andamento do seu processo.

O desperdício dos escassos recursos públicos não se justifica em nenhuma perspectiva. Sendo o flagranteado uma pessoa adulta, maior, capaz e tecnicamente representada no ato da audiência de custódia, ninguém melhor do que ele para decidir se há interesse, ou não, em acompanhar o desenrolar do procedimento. O Estado não precisa nem deve pretender tutelar esse indivíduo, presumindo que ele não será capaz de elaborar a escolha mais adequada à satisfação de seus interesses.

\subsection{Possíveis objeções}

Para prosseguir a exposição, é preciso enfrentar alguns possíveis questionamentos. 


\subsubsection{Celeridade em excesso?}

Não se trata propriamente de ter pressa, mas sim de reconhecer o desperdício de tempo e de dinheiro público.

A legislação brasileira torna absolutamente excepcional a rejeição da denúncia, pois, como se sabe, nessa etapa prevalece a presunção em favor da sociedade, bastando indícios de autoria, aliados à comprovação da materialidade, para a deflagração do processo penal. O mesmo raciocínio se aplica à absolvição sumária, viável apenas em hipóteses restritas.

Portanto, por imposição legal, o caminho frequente é o recebimento da denúncia e a não absolvição sumária.

É por isso que o juiz, contribuindo para a alocação eficiente de recursos, já pode antever o rumo procedimental e evitar a desnecessária feitura do mandado de citação para posterior cumprimento pelo oficial de justiça.

\subsubsection{Rejeição da denúncia e absolvição sumária}

Se a denúncia for eventualmente rejeitada ou o réu absolvido sumariamente, surgirão duas possibilidades.

A primeira é o juiz não aplicar essa nova modalidade de citação quando ele não vislumbrar a probabilidade de persecução penal na hipótese. O magistrado, por exemplo, diante de um caso de insignificância, pode não determinar esse comparecimento, já imaginando que provavelmente não haverá o oferecimento de denúncia.

A outra hipótese é a inversão do procedimento atual. Vale dizer: se não houver denúncia ou se a peça for rejeitada, aí sim o juiz pode se antecipar à data de comparecimento e determinar a intimação pessoal do investigado. Nesse caso, somente naquelas excepcionais hipóteses de rejeição da denúncia ou de absolvição sumária é que haveria a necessidade de deslocamento do servidor para a comunicação pessoal, se não disponibilizado meio eletrônico de contato. 
Ainda assim, o deslocamento seria único. É que, se não encontrado no endereço disponibilizado, o procedimento seria arquivado, sem qualquer prejuízo ao investigado.

\subsubsection{A ordem dos atos procedimentais}

Aqui, questiona-se: haveria a determinação de citação antes de iniciado o processo e da intimação para comparecimento em audiência antes da análise de eventual absolvição sumária?

A citação é um conceito jurídico-positivo, assim como a ordem dos atos procedimentais. Prova disso são as frequentes reformas processuais que criam novas modalidades de comunicação (edital, hora certa, eletrônica etc.).

Portanto, não há um conceito universal do que seja a citação. Seus contornos, limites e possibilidades são aqueles previstos em lei.

O que verdadeiramente importa é que não exista qualquer possibilidade de uma pessoa ser processada sem ter a real oportunidade de ciência da acusação formalizada pelo Estado a fim de que possa se defender.

$\mathrm{Na}$ hipótese proposta, esse risco simplesmente não existiria. Veja: o indivíduo foi preso, em regra pela Polícia Militar. A seguir, foi levado a uma Delegacia de Polícia, interrogado e posteriormente escoltado para o fórum, quando, então, diante do juiz, do seu defensor e do promotor de justiça, foi ouvido e expressamente advertido do dia em que deveria voltar ao fórum e quais as consequências do seu não comparecimento.

Diante dessa sequência de eventos naturais ao auto de prisão em flagrante, não existe qualquer justificativa lógica para defender que esse indivíduo teria a legítima expectativa de que seu procedimento simplesmente desapareceria. Ou seja, se ele acabou de ser preso em flagrante e acusado (não se pode esquecer de que a indicação do crime atribuído é uma das exigências legais) de praticar um crime, por qual razão se poderia supor que ele seria surpreendido com os desdobramentos ordinários do procedimento? Poderia essa pessoa, que foi expressamente advertida por um juiz na presença física de seu defensor, futuramente 
dizer que não fazia a mínima ideia de que estava sendo investigada (e poderia ser processada) por determinado crime?

Parece que a única forma de defender esse agente é infantilizando-o, é tratando-o não como uma pessoa livre, capaz de entender os fatos (embora tenha culpabilidade para fins penais, frisa-se!) e de decidir como pretende exercer o seu direito de defesa.

Ocorre que essa possibilidade afronta o texto constitucional e compromete a alocação adequada de recursos públicos.

Embora o sujeito tenha culpabilidade penal, embora possa constituir família e empreender, embora tenha sido preso (via de regra) na rua, embora possa votar e ser votado, ainda assim o Estado, inadimplente em quase tudo, decide presumir que essa pessoa não tem condições de retornar ao fórum dentro de alguns dias para,se quiser, cientificar-se do desenrolar da acusação criminal iniciada em seu desfavor. Pelo contrário, o Poder Público se sente confortável em despender recursos para deslocar um oficial de justiça, geralmente sobrecarregado, para ir em busca daquele cidadão que deixou as portas do fórum há pouquíssimos dias.

Perde a sociedade, com o atraso de todos os demais processos em andamento e com a possibilidade da não apuração dos fatos, caso o indivíduo não seja posteriormente encontrado. Perde o acusado, pois tratado como não merecedor de respeito como pessoa adulta. Perde, finalmente, o Poder Judiciário, que se vê obrigado a praticar atos desnecessários, sobrecarregando os poucos servidores e comprometendo o bom andamento da pauta judicial.

\subsubsection{Compatibilidade com o direito de defesa}

O invólucro da forma deve ceder diante do poder da substância. Para que o sistema funcione de modo racional e adequado, não se pode admitir a invocação de argumentos que interditem o avanço da discussão.

É justamente do que se trata ao se analisar o direito de defesa, invocado excessiva e genericamente para inviabilizar o aperfeiçoamento da legislação criminal brasileira. 
Não se vê qualquer necessidade de destacar as conquistas históricas representadas pelo reconhecimento do amplo direito de defesa na história da humanidade. Incorreria em verdadeira tautologia, pois basta ver que a premissa teórica da exposição do autor deste artigo é justamente a defesa da liberdade do homem frente ao Estado. Ora, se o processo penal é o mecanismo legítimo para a imposição da máxima restrição suportada pela liberdade humana (a física), é evidente que se reconhece no mais amplo, livre e desembaraçado exercício do direito de defesa uma das conquistas mais expressivas e relevantes na luta do homem pela contenção do poder do Estado.

Todavia, defender o direito de defesa não pode significar a infantilização de pessoas adultas. Não pode significar o desperdício de dinheiro público em um país pobre e carente. Não pode significar a complacência com o uso predatório do sistema recursal brasileiro. Não pode significar o congestionamento invencível na máquina pública. Não pode significar, enfim, a impunidade pelo cansaço, e não pela inocência, ainda que duvidosa.

No caso, não há nenhuma possibilidade de ofensa ao direito de defesa. Conforme visto, o custodiado, se tratado como um adulto livre, terá a ampla possibilidade de escolher se participa ou não do procedimento. Se quiser participar, a ele serão deferidas todas as faculdades inerentes à autodefesa. Caso contrário, a tutela de seus interesses ficará a cargo da defesa técnica, pública ou particular.

Aúnica forma de reconhecer ofensa ao direito de defesa, insiste-se, é se presumir que o agente será surpreendido pela existência do processo penal, sobre o qual não pôde, portanto, se manifestar. Todavia, somente se o tratar como incapaz de gerir seus próprios interesses, em desconsideração à sua condição de homem livre, é que tal conclusão seria viável.

\subsubsection{E, quanto aos casos específicos em que não for possível, por qualquer razão o comparecimento pessoal posterior?}

Grau (2020, p. 77), citando Aristóteles, faz uma observação bastante útil ao enfrentamento da questão: 
Aristóteles distingue a equidade e o equitativo, relacionando-os ao justo. O equitativo, embora seja justo, não é o justo segundo a lei, senão um corretivo da justiça legal. A razão disso está em que a lei é sempre geral, e há casos em relação aos quais não é possível estipular um enunciado geral que se aplique com retidão. A lei não toma em consideração senão os casos mais frequentes, sem ignorar os erros que isso possa importar. Nem por isso ela é menos correta, porque a culpa não está na lei, nem no legislador, mas, sim, na natureza das coisas. E assim é porque, em razão de sua própria essência, a matéria das coisas da ordem prática se reveste do caráter de irregularidade.

O que se pretende dizer é o seguinte: sempre haverá hipótese em que o indivíduo flagranteado não poderá comparecer ao fórum. Pode ser, por exemplo, que haja alguma dificuldade de locomoção ou financeira. No entanto, tais circunstâncias não invalidam a tentativa de aprimorar o procedimento judicial, pois as singularidades da vida naturalmente escapam do alcance do legislador. A rigor, acredita-se que o caráter excepcional desses casos apenas confirmará o acerto da proposta, útil à generalidade das hipóteses.

O que se defende, portanto, é que os casos específicos sejam resolvidos de acordo com as suas nuances. Conforme já exposto, essa nova modalidade de citação será opcional, o que, por si só, parece resolver as possíveis dificuldades práticas de sua implementação. Se não houver a real possibilidade de comparecimento, basta que sejam aplicadas as hipóteses tradicionais de comunicação processual.

Especificamente no que diz respeito às dificuldades financeiras, talvez seja conveniente uma análise econômica do efetivo custo da citação tradicional, pois é possível que a disponibilização de vale-transporte represente uma alocação mais adequada e eficiente do dinheiro do povo.

Outro ponto que parece importante: a impossibilidade de comparecimento ao fórum deve ser absoluta. Diz-se isso já antecipando às eventuais discussões envolvendo pessoas hipossuficientes do ponto de vista financeiro.

Neste específico ponto, é importante não perder de vista que pessoas financeiramente vulneráveis devem ser tratadas com o mesmo respeito 
e a mesma consideração. Do Estado, não precisam de tutela, pois são pessoas adultas e igualmente capazes, não havendo autorização legal ou constitucional para que se presuma que tais indivíduos, só pelo fato de terem pouco dinheiro, sejam incapazes de decidir os rumos da própria vida. A ausência de dinheiro deve ser resolvida, portanto, no plano estritamente econômico, por meio de benefícios financeiros. Ou seja, se a pessoa, por ser pobre na acepção legal, não puder pagar as custas processuais e contratar um advogado particular, então o Estado afasta essas duas barreiras, dispensando o pagamento das custas e direcionando o indivíduo à Defensoria Pública ou ao advogado dativo. Nada mais. Qualquer tentativa adicional de tutela, ainda que sob generosas pretensões, parece não apenas embaraçoso aos profissionais habilitados à representação do hipossuficiente, mas também exercício de vedado paternalismo estatal, pois parte da premissa de que o agente público reúne melhores condições de deliberar sobre os rumos e os propósitos da vida de um semelhante.

É verdade que pessoas financeiramente carentes possuem, via de regra, pouca instrução formal, justamente por conta dos conhecidos percalços existentes no acesso a uma educação de qualidade em um país tão desigual como o Brasil. Todavia, novamente se insiste em dizer que isso não permite que o Estado se arvore na condição de protetor da vida privada. Afinal, questões técnicas serão decididas por um profissional do direito muito bem preparado, e a premissa implícita de quem pratica um crime é a potencial consciência da ilicitude, como elemento da culpabilidade. Vale dizer: a pessoa processada é maior de idade, está bem representada tecnicamente e possui capacidade de compreender o caráter ilícito do fato que lhe é imputado, de modo que também reúne plenas condições de entender a necessidade de comparecimento ao fórum no dia designado.

Finalmente, convém uma palavra sobre a boa-fé processual.

Didier (2019, p. 137), sobre o princípio:

[...] Sempre que exista um vínculo jurídico, as pessoas envolvidas estão obrigadas a não frustrar a confiança razoável do outro, devendo comportar-se como se pode esperar de uma pessoa de boa-fé. Como 
acontece com qualquer relação jurídica, a boa-fé recai também sobre as relações processuais [...] se mesmo na guerra a ética há de ser preservada, como não defender a existência de um princípio da boa-fé processual, em que, ainda que apenas metaforicamente, de modo civilizado e sob supervisão do juiz, as partes 'guerreiam' por seus interesses?

Se se considerar que o princípio da boa-fé está previsto no código de processo civil, aplicado analogicamente ao processo penal, bem como que pode ser extraído da Constituição Federal, a consequência necessária é que também os autores do processo penal devem se comportar com lealdade.

O direito de defesa no Brasil possui contornos amplos e abrangentes. Basicamente todas as conquistas civilizatórias nesse campo estão consagradas neste país. Aqui, no momento em que é preso em uma das específicas hipóteses de flagrante, o indivíduo somente pode ser algemado excepcionalmente. Seu telefone, se apreendido, não pode ser acessado. Após a prisão, é levado a uma Delegacia de Polícia. Ali, o conduzido será informado de todos os seus direitos, dentre os quais, o de ficar em silêncio. Ainda, será informado quem são os responsáveis por sua prisão e terá acesso a advogado. Sua família será comunicada. Em menos de 24 horas, será apresentado a um juiz, a um advogado e a um promotor de justiça. Será novamente ouvido para que sejam conhecidas as circunstâncias de sua prisão, a fim de que seja resguardada sua integridade psicofísica. Após, o juiz deverá conceder a liberdade, aplicando ou não uma das medidas cautelares diversas da prisão, que só pode ser mantida em casos excepcionais devidamente motivados. Mantida a prisão, o cidadão pode, mesmo sem advogado, impetrar sucessivos Habeas Corpus em todas as instâncias judiciais no país. Se denegados, poderá voltar a impetrá-los outras tantas vezes ao longo do procedimento. Iniciado o processo penal, será citado e poderá esclarecer se deseja a nomeação de um Defensor Público ou advogado dativo. Poderá apresentar suas testemunhas e produzir todas as provas que desejar, gratuitamente. No dia da audiência, será ouvido por último. Se preferir, poderá se manter em silêncio, sem qualquer prejuízo à sua defesa. Suas alegações finais 
serão protocoladas por último. A condenação pressupõe robusta prova produzia pela acusação. A dosimetria da pena, de igual forma, é cada vez mais vinculada pela jurisprudência. Após a condenação, o condenado tem à sua disposição amplo catálogo recursal. Se houver divergência entre os julgadores coletivos, novos recursos lhe são disponibilizados. Em todas as instâncias, a defesa tem o direito de, além de razões escritas, apresentar seus argumentos oralmente. O início da execução penal está condicionado à chancela da Suprema Corte do país. Mesmo assim, ainda que iniciado o processo de execução penal, a todo momento os fatos poderão ser reapreciados por meio da revisão criminal.

Em suma: o direito de defesa no Brasil é levado a sério. Em um país com tantas carências como o Brasil, uma das faltas não é o de direito de defesa.

Excessivas ou não, são essas as regras do jogo do processo penal brasileiro. A defesa pode, portanto, manusear cada uma delas da forma que lhe for mais conveniente. Ao fazê-lo, estará dento da legalidade.

No entanto, diante de um sistema que tutela e promove direito de defesa e que exige a boa-fé e a lealdade de todos os contentores, o que se espera é que o réu mantenha com o processo judicial a mesma relação de seriedade e respeito.

Volta-se ao ponto: a impossibilidade de comparecimento ao fórum deve ser absoluta. Não se pode admitir, por exemplo, que um indivíduo preso em flagrante delito em plena via pública, depois, inexplicavelmente, negue possuir condições de comparecer ao fórum dentro de poucos dias. A alegação não pode ser validamente inserida dentre as múltiplas prerrogativas inerentes ao direito de defesa, pois parece levar pouco a sério o sistema de justiça, tratando-se, na verdade, de ato contrário à boa-fé processual ${ }^{4}$.

4. Outro abuso do direito de defesa é o pedido de interrogatório de réus foragidos, o que merece aprofundada reflexão. 


\subsection{Formas de implementação da proposta}

Inicialmente, foram pensadas duas alternativas para concretizar a proposta, mas, ao fim, ambas se revelaram insuficientes.

A primeira opção seria a invocação do art.191 do código de processo civil, que regulamenta o calendário processual em âmbito cível. Embora não haja aparentes obstáculos para a importação do instituto ao processo penal, a sua voluntariedade, na prática, dificultaria a implementação da proposta.

Outra possibilidade seria a fixação do comparecimento para a citação como medida cautelar diversa da prisão, admitindo aqui a existência do poder geral de cautela em âmbito penal. Todavia, nesse caso, pensa-se que incorreria em contradição. É que a premissa teórica que se sustenta é a defesa da liberdade, o reconhecimento de que pessoas adultas, capazes e residentes em um país livre podem decidir sozinhas os rumos de sua própria vida. No entanto, se fixado como medida cautelar, o não comparecimento importaria na decretação da prisão preventiva. $\mathrm{Na}$ prática, então, o indivíduo seria obrigado a se apresentar, o que colide com esta tese, que é no sentido da disponibilidade da autodefesa penal. Sendo o procedimento criminal, em relação ao réu, um instrumento de defesa, a ele cabe decidir, como pessoa livre, se pretende ou não acompanhar o andamento do feito.

Assim, diante da inconsistência das duas alternativas, o ideal é que a nova modalidade de citação seja prevista e regulamentada por lei. $\mathrm{O}$ parlamento, afinal, é o local adequado para o debate de ideias.

\section{CONCLUSÃO}

Antes de concluir, entende-se importante voltar à questão do método de Popper.

Nos termos explorados anteriormente, ele defende uma metodologia de avanço gradual e parcelar. Em vez de se buscar uma solução global e universal aos problemas, propõe que se avance progressivamente, passo a passo, o que permite corrigir os rumos na hipótese de erros. 
A proposta do método parece ser muito adequada. O Brasil é um país complexo, desigual e de proporções continentais. O nível de consenso exigido para grandes e profundas reformas dificilmente é alcançado, especialmente diante da fratura política a que se está exposto.

Por isso é que, identificado o problema, o ideal é que se esteja disposto ao primeiro passo, relegando os demais a seu devido tempo e processo de maturação.

Diante desse método de trabalho e análise é que se propõe o presente texto. A sugestão formalizada por estas páginas é apenas um passo para o reconhecimento da liberdade humana como vetor da relação estabelecida entre Estado e particulares. Um passo para a contribuição, ainda que mínima, para a diminuição da sobrecarga das unidades criminais, dos oficiais de justiça e, em última análise, um passo para que o processo criminal, independentemente do resultado do julgamento e observando todas as garantias históricas que se agrupam sob a proteção do direito de defesa, possa ser concluído em tempo razoável.

\section{REFERÊNCIAS}

BARROSO, Luís Roberto. A dignidade da pessoa humana no direito constitucional contemporâneo. Belo Horizonte, Fórum, 2021.

BRASIL. Constituição da República Federativa do Brasil (1988). Disponível em: http://www.planalto.gov.br/ccivil_03/constituicao/ constituicao.htm. Acesso em: 22 jun. 2021.

BRASIL. Código de Processo Civil (2015). Disponível em: http:// www.planalto.gov.br/ccivil_03/_ato2015-2018/2015/lei/113105.htm. Acesso em: 21 jun.2021.

BRASIL. Código de Processo Penal (1941). Disponível em: http:// www.planalto.gov.br/ccivil_03/decreto-lei/del3689.htm. Acesso em: 21 jun. 2021.

DIDIER Jr., Fredie, Curso de direito processual civil: introdução ao direito processual civil, parte geral e processo de conhecimento. 21. ed. Salvador, JusPodivm, 2019. 
GRAU, Eros Roberto. Por que tenho medo dos juízes (a interpretação/aplicação do direito e os princípios). 10. ed. São Paulo, Malheiros, 2021.

LLOSA, Mário Vargas. O chamado da tribo. Rio de Janeiro: Objetiva, 2018.

MANKIW, N. Gregory. Introdução à economia. 8. ed. São Paulo, CENGAGE, 2020.

PEREIRA, Luiz Carlos Bresser; SPINK, Peter (org.). Reforma do estado e administração pública gerencial. 7. ed. Rio de Janeiro, FGV Editora, 2006.

POPPER, Karl. A sociedade aberta e seus inimigos. Lisboa: 70, 2021. v. 2.

RODRIGUES, Alex. Justiça em números 2020: nova edição confirma maior produtividade do Judiciário. CNJ, 2020. Disponível em: https:/www.cnj.jus.br/justica-em-numeros-2020-nova-edicao-confirma-maior-produtividade-do-judiciario/. Acesso em: 20 jun.2022.

Recebido em: 30/06/2021

Aprovado em: 05/07/2021 